\title{
CORRECTION
}

\section{Correction to: Hugoniot Measurements Utilizing In Situ Synchrotron X-ray Radiation}

D. J. Miller ${ }^{1,2}$ - R. S. Crum ${ }^{1}$ - M. A. Homel ${ }^{1}$ - D. E. Eakins ${ }^{3}$ - D. J. Chapman ${ }^{3}$. J. C. Z. Jonsson ${ }^{3}$ M. E. Rutherford ${ }^{3}$. E. M. Escauriza ${ }^{3}$. L. C. Smith ${ }^{3}$ - E. B. Herbold ${ }^{1}$. J. Lind ${ }^{1}$ - M. C. Akin ${ }^{1}$

Published online: 1 March 2019

(c) Society for Experimental Mechanics, Inc 2019

\section{Correction to: Journal of Dynamic Behavior of Materials https://doi.org/10.1007/s40870-019-00187-x}

E. M. Escauriza's appeared incorrectly on the original publication of this article. It is corrected here.

Publisher's Note Springer Nature remains neutral with regard to jurisdictional claims in published maps and institutional affiliations.

The original article can be found online at https://doi.org/10.1007/ s40870-019-00187-x.

D. J. Miller

dmille84@ vols.utk.edu

1 Lawrence Livermore National Laboratory, Livermore, CA, USA

2 Department of Nuclear Engineering, University of Tennessee, Knoxville, TN, USA

3 Department of Engineering Science, University of Oxford, Oxford OX1 5PF, UK 